\title{
Rotating Shadowband Spectroradiometer Handbook
}

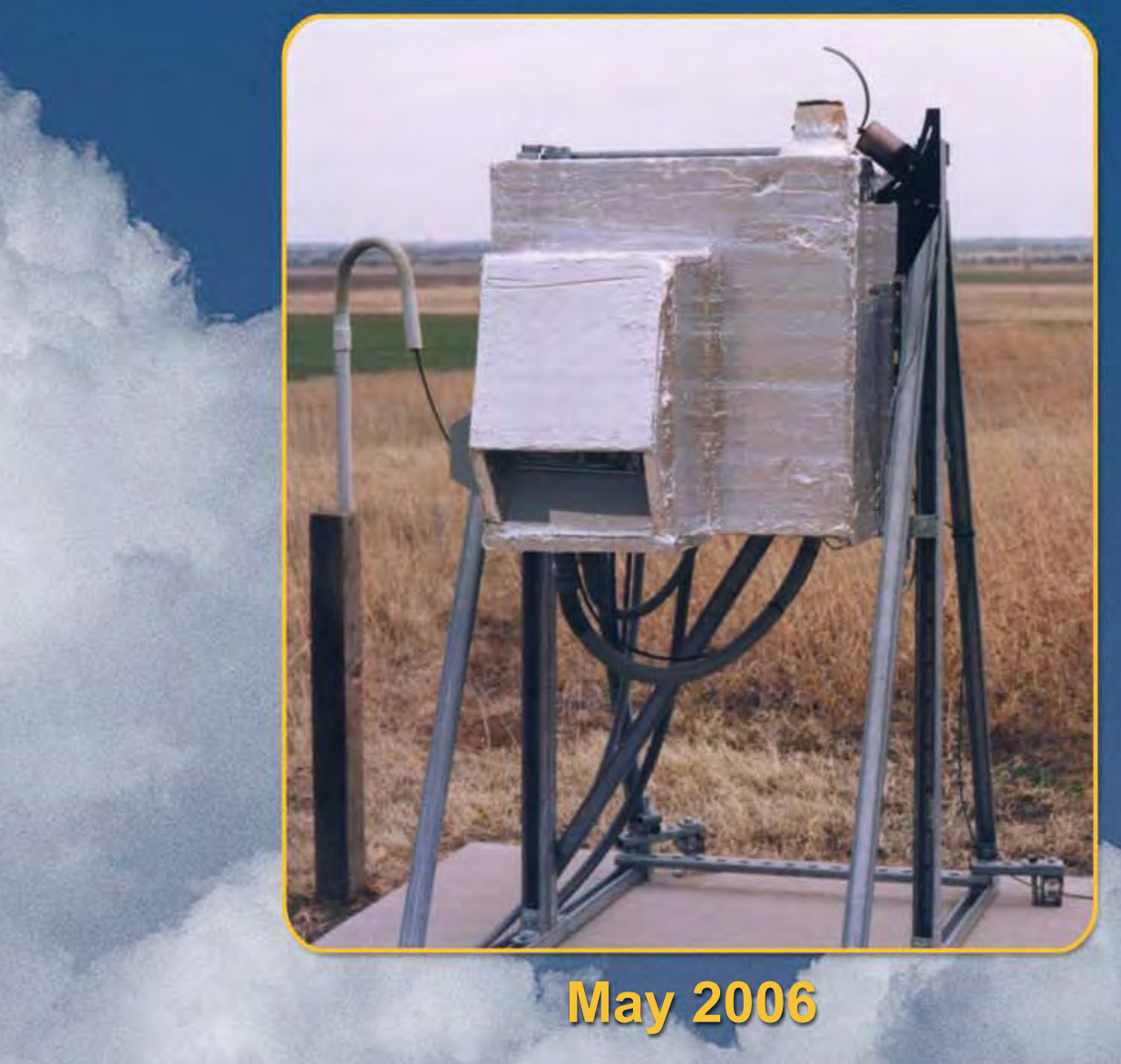

Work supported by the U.S. Department of Energy Office of Science, Office of Biological and Environmental Research 


\section{Rotating Shadowband Spectroradiometer (RSS) Handbook}

May 2006

P. Kiedron

J. Schlemmer

M. Klassen

Work supported by the U.S. Department of Energy,

Office of Science, Office of Biological and Environmental Research 


\section{Contents}

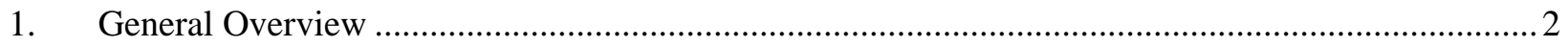

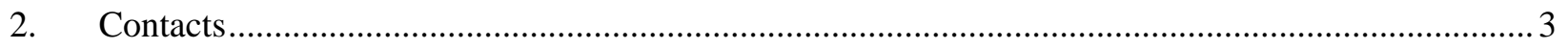

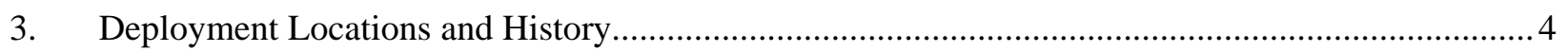

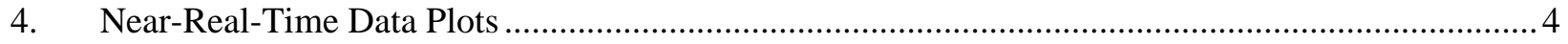

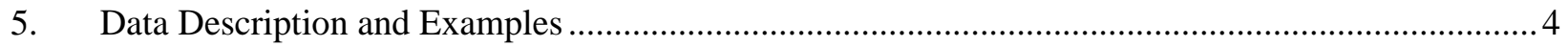

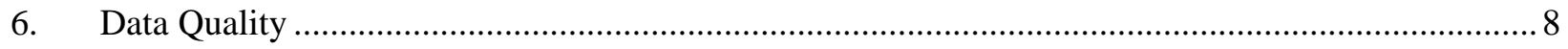

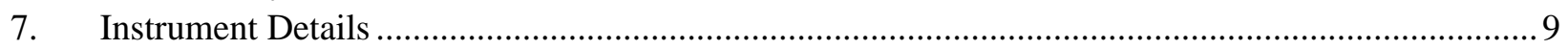

\section{Figures}

1. From right to left: RSS105, UV-RSS104 and RSS103 in May 2003........................................... 2

2. 1-sigma photon and read noise in direct and diffuse irradiances ................................................. 7

3. RSS optics (IC-integrating cavity, S-slit, SH-shutter, L1-collimating lens, P1, P2-prisms, L2-

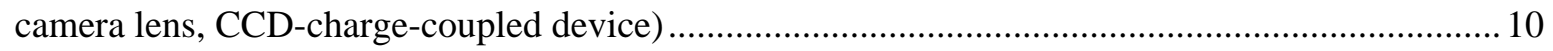

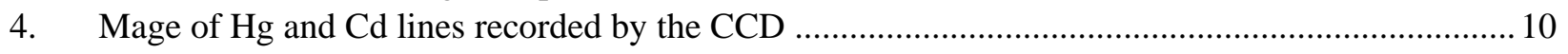

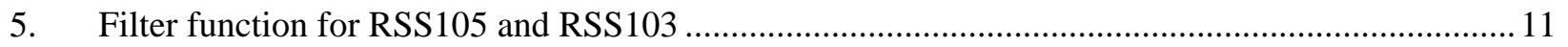

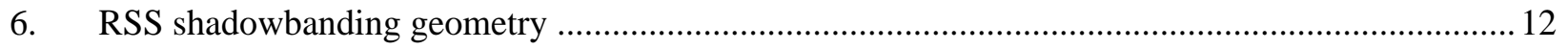

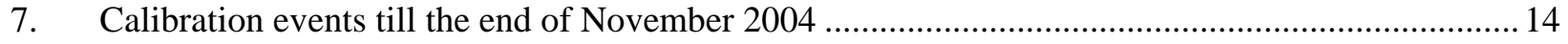

\section{Tables}

$1 . \quad 2$

2.

3. 


\section{General Overview}

The rotating shawdowband spectroradiometer (RSS) implements the same automated shadowbanding technique used by the multifilter rotating shadowband radiometer (MFRSR), and so it too provides spectrally-resolved, direct-normal, diffuse-horizontal, and total-horizontal irradiances, and can be calibrated in situ via Langley regression. The irradiance spectra are measured simultaneously at all spectral elements (pixels) in 360-nm to 1050-nm range. Figure 1 depicts the RSS105 at the Southern Great Plains (SGP) Oklahoma site with the UV-RSS104 and RSS102 during the Aerosol Intensive Operational Period (IOP) in May 2003.

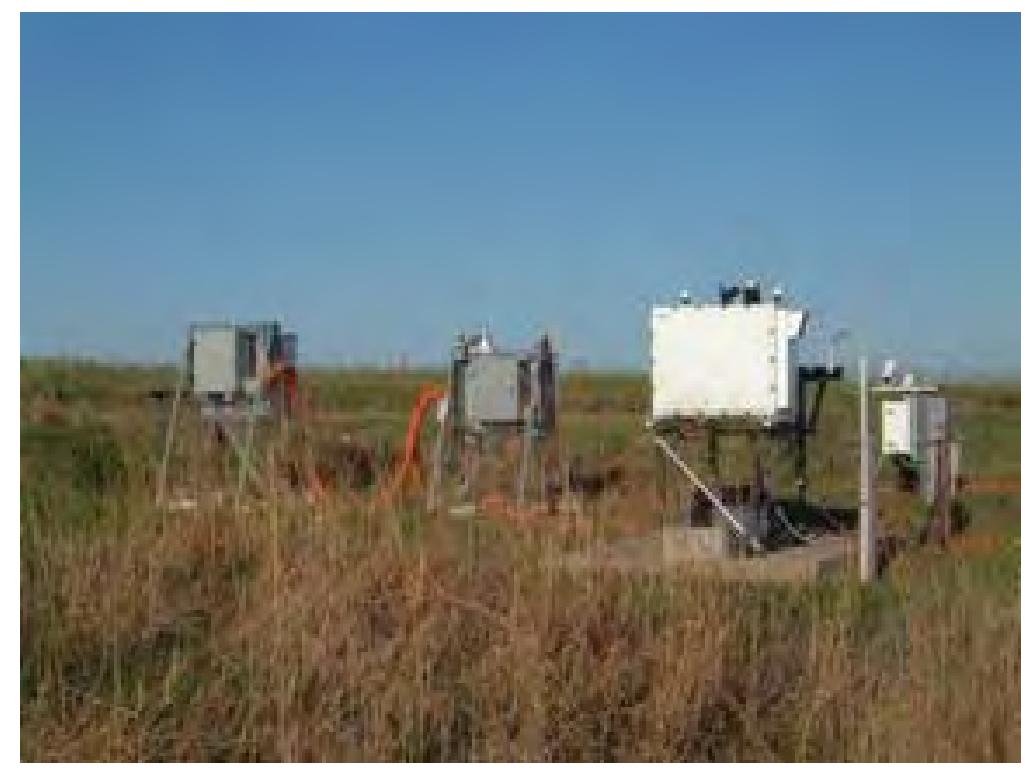

Figure 1. From right to left: RSS105, UV-RSS104 and RSS103 in May 2003

The currently deployed RSS105 was preceded with two prototypes, RSS103 and RSS102, which also operated at SGP in three distinct periods since August 1997 (see Table 1). Data from the two prototypes and RSS105 till March 30, 2006 are available at http://iop.archive.arm.gov/arm-iop/0special-data/asrcrss/ in ascii format. All RSS105 data are available from ARM Archives in netCDF format. RSS105 data in ARM Archives are lamp calibrated irradiances. The accuracy of irradiance produced by RSS is expected to be better than $\pm 5 \%$ that includes calibration and instrument stability errors. Higher accuracy can be obtained when the responsivity is tied to the solar extraterrestrial irradiance via Langley regression. This approach is recommended when high precision measurements of optical depth are required. The calibration constants from Langley regressions (so called Vo's) are available from the IOP server http://iop.archive.arm.gov/arm-iop/0special-data/asrc-rss/rss105/langley/ .

Table 1.

\begin{tabular}{|l|l|l|l|}
\hline \multicolumn{3}{|c|}{ Data Availability } \\
\hline & RSS105 & RSS103 & RSS102 \\
\hline
\end{tabular}




\begin{tabular}{|l|l|l|l|}
\hline Location & SGP & SGP & SGP \\
\hline Operational epochs & $05 / 09 / 03$ - Present & $\begin{array}{l}09 / 29 / 01-06 / 27 / 02 \\
08 / 12 / 97-10 / 05 / 98\end{array}$ & $07 / 22 / 99-08 / 04 / 00$ \\
\hline Measurement period & From sunrise to sunset \\
\hline Measurement rate & 1 shadowbanding cycle per min \\
\hline $\begin{array}{l}\text { Number of spectra } \\
\text { per day }\end{array}$ & From 570 spectra in Winter to 870 spectra in Summer \\
\hline
\end{tabular}

Note: RSS103 was also deployed at the North Slope of Alaska (NSA) site from 03/04/1999 till 08/16/1999. Data are available from Atmospheric Sciences Research Center (ASRC) server only.

Irradiances from RSS's were used in research resulting in several significant scientific contributions. Michalsky et al. (1999) determined absorption cross-sections of O2-O2; Min et al. (1999 and 2001) developed methods to measure cloud optical depth from oxygen A-band that lead to cloud detection beyond microwave radar sensitivity; Kiedron et al. (1999) utilized RSS in irradiance standards intercomparison; Mlawer et al. (2000) used RSS direct and diffuse spectra to validate line-by-line clear sky shortwave model; Schmid et al. (1999) used aerosol retrieved from RSS; Harrison et al. (1999 and 2003) detected significant accuracy issues in solar source functions below 450nm; Michalsky et al. (2001) retrieved water vapor column; Kiedron et al. (2001 and 2003) retrieved water vapor column in Arctic in both clear sky and overcast conditions; most recently Gianelli et al. (2005) used RSS data to retrieve NO2 column at SGP.

\section{Contacts}

\subsection{Mentor}

Peter Kiedron (Instrument Mentor)

Atmospheric Research Center

SUNY at Albany

251 Fuller Road

Albany, NY 12203

Phone: 518-437-8737

Fax: 518-437-8711

E-mail: kiedron@asrc.cestm.albany.edu

Jim Schlemmer (Data Processing)

Atmospheric Research Center

SUNY at Albany

251 Fuller Road

Albany, NY 12203

Phone: 518-437-8718

Fax: 518-437-8711

E-mail: jim@asrc.cestm.albany.edu

Mark Klassen (Instrument Calibration)

SGP Cart Site Operations 
Phone: 580-388-4053

E-mail: markk@ops.sgp.arm.gov

\subsection{Instrument Developer}

RSS105: Yankee Environmental Systems, Airport Industrial Park, 101 Industrial Blvd., Turners Falls, MA 01376 (413) 863-0200

RSS102 \& RSS103: ASRC, SUNY at Albany, 251 Fuller Road, Albany, NY 12203 (contact: P. Kiedron at kiedron@asrc.cestm.albany.edu or L. Harrison lee@asrc.cestm.albany.edu)

\section{Deployment Locations and History}

This section is not applicable to this instrument.

\section{Near-Real-Time Data Plots}

This section is not applicable to this instrument.

\section{Data Description and Examples}

\subsection{Data File Contents}

\subsubsection{Primary Variables and Expected Uncertainty}

The primary quantities measured by the system are:

1. the direct normal solar spectral irradiance $\left(\mathrm{W} / \mathrm{m}^{2} / \mathrm{nm}\right)$

2. the total horizontal solar spectral irradiance $\left(\mathrm{W} / \mathrm{m}^{2} / \mathrm{nm}\right)$

3. the diffuse horizontal solar spectral irradiance $\left(\mathrm{W} / \mathrm{m}^{2} / \mathrm{nm}\right)$.

Each of these quantities is measured in 360-nm-1050-nm range. In the case of RSS105, 1001 pixels (adjacent spectral elements) are simultaneously measured in this range. The resolution is pixeldependent. Table 2 lists Full Width at Half Maximum (FWHM) at seven selected wavelengths, both in $\mathrm{nm}$ and in pixels. The exact filter function for each pixel is provided in files available at: http://iop.archive.arm.gov/arm-iop/0special-data/asrc-rss/

\section{Table 2.}

\begin{tabular}{|l|l|l|l|}
\hline \multicolumn{3}{|c|}{ Spectral Characteristics } \\
\hline & RSS105 & RSS103 & RSS102 \\
\hline Number of pixels & 1024 & 512 & 1024 \\
\hline $\begin{array}{l}\text { Nominal Spectral Range } \\
\text { (NSR)[nm] }\end{array}$ & $360-1050$ & $360-1050$ & $360-1050$ \\
\hline $\begin{array}{l}\text { Number of Pixels within } \\
\text { NSR }\end{array}$ & 1001 & 442 & 988 \\
\hline Resolution (FWHM) [nm]/[pixels] & & \\
\hline
\end{tabular}




\begin{tabular}{|l|l|l|l|}
\hline @400nm & $0.37 / 1.56$ & $1.24 / 2.32$ & $0.37 / 1.52$ \\
\hline @500nm & $0.62 / 1.36$ & $2.57 / 2.47$ & $1.14 / 2.44$ \\
\hline$@ 600 \mathrm{~nm}$ & $1.05 / 1.40$ & $4.84 / 2.81$ & $1.77 / 2.32$ \\
\hline$@ 700 \mathrm{~nm}$ & $1.57 / 1.44$ & $7.80 / 3.12$ & $2.21 / 2.00$ \\
\hline$@ 800 \mathrm{~nm}$ & $2.16 / 1.52$ & $11.02 / 3.37$ & $2.53 / 1.75$ \\
\hline @900nm & $2.79 / 1.63$ & $14.32 / 3.61$ & $2.81 / 1.62$ \\
\hline @1000nm & $3.42 / 1.78$ & $17.11 / 3.83$ & $3.10 / 1.58$ \\
\hline
\end{tabular}


Table 2. (cont'd)

\begin{tabular}{|l|l|l|l|}
\hline \multicolumn{4}{|c|}{ Spectral Characteristics } \\
\hline Filter functions & Gaussian & Gaussian & Gaussian \\
\hline 95\% below maximum & $\begin{array}{l}\text { rss103_GaussWidth } \\
\text { Gaussian parameter from }\end{array}$ & rss105_GaussWidth & rrs102_GaussWidth \\
\hline $\begin{array}{l}\text { Below 95\% is defined by } \\
\text { following files }\end{array}$ & $\begin{array}{l}\text { rss105_ff_respEQ1 } \\
\text { rss105_respQM } \\
\text { rss105_RespW }\end{array}$ & $\begin{array}{l}\text { rss103_ff_respEQ1 } \\
\text { rss103_RespQM } \\
\text { rss103_RespW }\end{array}$ & $\begin{array}{l}\text { rss102_ff_respEQ1 } \\
\text { rss102_RespQM } \\
\text { rss102_RespW }\end{array}$ \\
\hline
\end{tabular}

Note: In RSS105 the pixel 523 (approximately at $503 \mathrm{~nm}$ ) is dead. The average of 522 and 524 pixels is reported instead resulting in increased resolution at this pixel.

\subsubsection{Definition of Uncertainty}

\section{Overall Uncertainties for Primary Quantities Measured}

Photon and Read Noise: The read noise of the charge-coupled device (CCD) and Poisson photon noise were characterized before deployment. Also, data from each calibration event are analyzed to verify whether noise parameters remain unchanged. The standard deviation of this noise is calculated for every pixel of every scan and submitted with calibrated data (RSS105). The relative value of this noise is larger in absorption bands and strong Fraunhofer lines and near $360 \mathrm{~nm}$ and $1050 \mathrm{~nm}$. See Figure 2 for typical noise values in percent of diffuse and direct irradiances.

Radiometric Calibration Error: We estimate that calibration transfer errors are less than $\pm 2 \%$ for each individual calibration.

Absolute Radiometric Scale Error: The National Institute of Standards of Technology (NIST) specifies that the individual FEL lamp's accuracy is as large as $\pm 4 \%$. However, we have reasons to believe that the methodology used to calibrate RSS yields lower errors. We base this on results found in papers by Kiedron et al. (1999) when many calibration standards were compared, including Licor and on RSSderived extraterrestrial spectrum that differs less than 4\% from the accepted standard of extraterrestrial spectrum (see Harrison et al. [1999 and 2003]) for wavelengths larger than $450 \mathrm{~nm}$. 


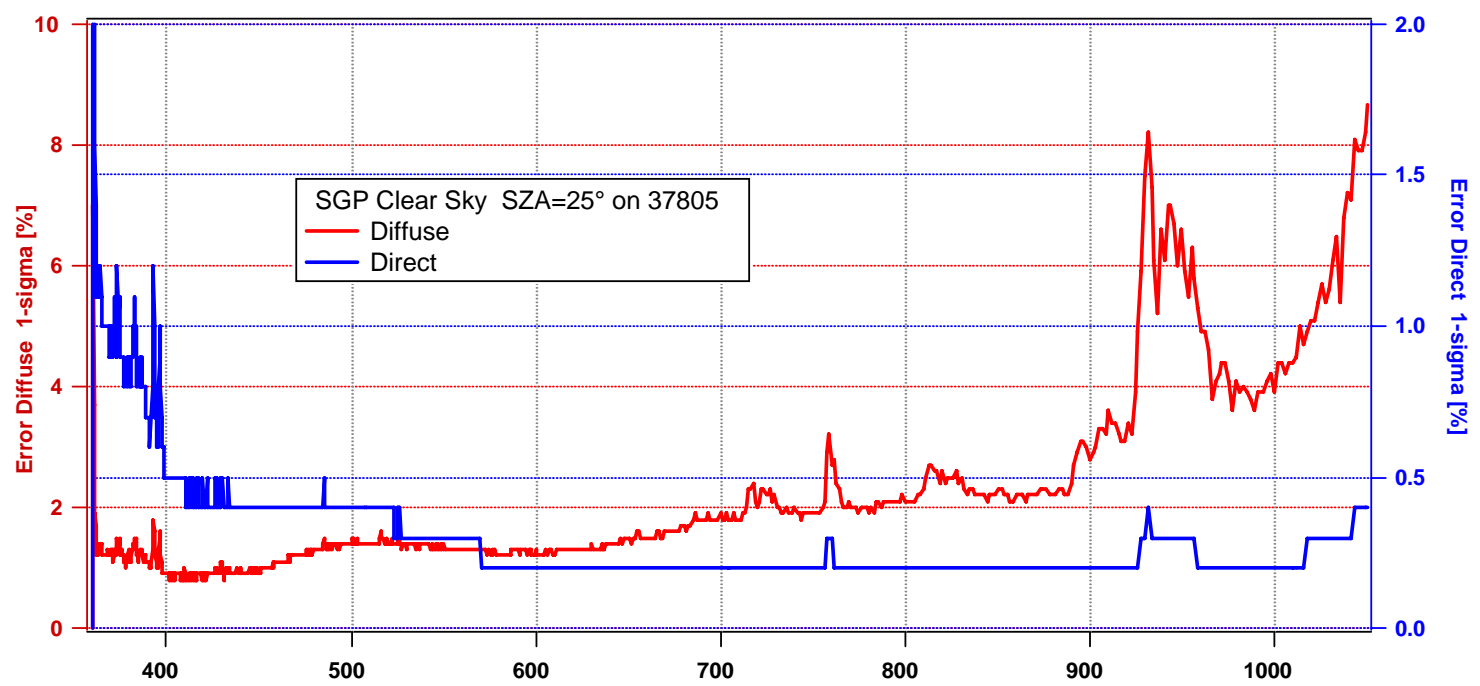

Figure 2. 1-sigma photon and read noise in direct and diffuse irradiances

Nonlinearity: The nonlinearity is detected and characterized from calibration data and then corrected in each scan of RSS105. We estimate that uncertainty because of this correction may result in errors of up to $\pm 1 \%$ in the regions of the spectra where signal is strong.

Wavelength errors: Because of temperature changes of the optics and mechanical stress, there is a slight spectral shift during daily measurement. The shifts are small (less than 0.5 pixels). Nevertheless, they are detected in each scan and applied to responsivity. A special correlation technique with Fraunhofer spectrum is used to detect these wavelengths shifts.

Stability: During the first several months of operation, RSS105 exhibited strong responsivity drift. The rate of drift showed a steady decline. As of November 2004 the drift appears to be less than 1\% per month. Bimonthly calibrations and use of interpolated responsivity assures that the drift has no impact on the final data quality.

Stray Light: When comparing RSS with modeled irradiance, one has to keep in mind that the modeled irradiance must be calculated with the exact RSS filter functions (See Figure 5). If truncated versions of these functions are used, then some discrepancies appear in absorption bands in the form of a residual stray light. On the other hand, it is possible to remove the stray light from RSS spectra by the method of deconvolution (see Kiedron et al. [2002]); however, it is simpler to calculate the modeled spectra using exact RSS filter functions.

\subsubsection{Secondary/Underlying Variables}

This section is not applicable to this instrument.

\subsubsection{Diagnostic Variables}

This section is not applicable to this instrument. 


\subsubsection{Data Quality Flags}

This section is not applicable to this instrument.

\subsubsection{Dimension Variables}

This section is not applicable to this instrument.

\subsection{Annotated Examples}

This section is not applicable to this instrument.

\subsection{User Notes and Known Problems}

Automated Quality Control/flagging contained within netCDF files.

While netCDF files of processed and calibrated RSS data are not produced at this point, we denote missing data as -999 .

\subsection{Frequently Asked Questions}

This information is currently unavailable.

\section{Data Quality}

\subsection{Data Quality Health and Status}

No routine implementation.

\subsection{Data Reviews by Instrument Mentor}

Instrument Mentor Quality Control Checks

- QC frequency: Daily

- QC delay: Day+2

- QC type: Graphical plots

- Inputs: Raw data

- Outputs: Summary reports

- Reference:

\section{Site Scientist/Data Quality Office Quality Control Checks}

Not implemented yet. 
Value-Added Procedures and Quality Measurement Experiments

No value added products have been implemented yet.

Examples of Data

See data files at http://iop.archive.arm.gov/arm-iop/0special-data/asrc-rss/ .

Data Quick Looks/Near Realtime

Not available yet.

\subsection{Data Assessments by Site Scientist/Data Quality (DQ) Office}

This section is not applicable to this instrument.

\subsection{Value-Added Procedures and Quality Measurement Experiments}

This section is not applicable to this instrument.

\section{Instrument Details}

\subsection{Detailed Description}

\subsubsection{List of Components}

Not available yet.

\subsubsection{System Configuration and Measurement Methods}

\section{Spectrograph and CCD}

The optics of RSS is depicted in Figure 3 with the actual ray-trace. All lenses are plano-convex singlets; achromatization was not attempted to keep the number of surfaces to a minimum. Because of the chromatic aberrations, the image plane is oblique to the optical axis. For this reason the CCD reflects some of impinging light away from the optical system into the dark cavity. The CCD has no window to avoid reflections between the window and the surface of the CCD. 


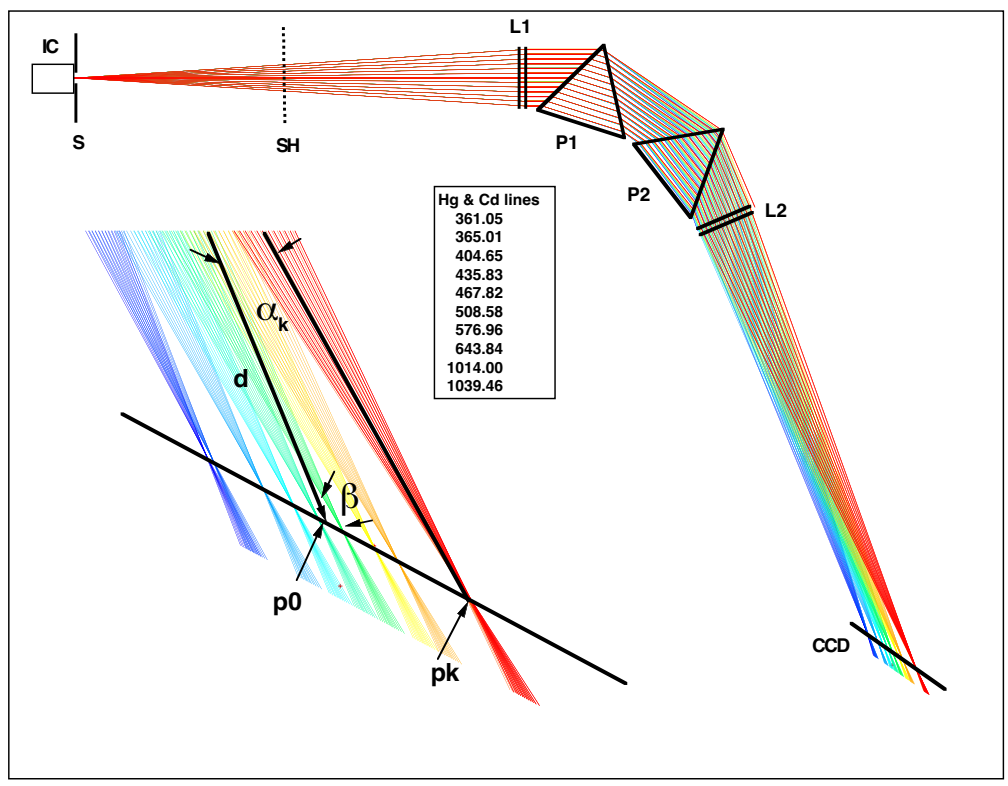

Figure 3. RSS optics (IC-integrating cavity, S-slit, SH-shutter, L1-collimating lens, P1, P2-prisms, L2camera lens, CCD-charge-coupled device)

Not shown in Figure 3 is the sandwich of two color glass filters. In RSS105 they are located between slit and collimating lens. They reduce dynamic range and increase the out-of-band rejection in UV and near infrared (NIR) regions in particular. However, we have not yet confirmed our hypothesis that they contribute to instrument radiometric instability.

The slit image is formed on the two-dimensional CCD (Figure 4), but during the operation all rows within the image are binned during a single readout. The exposure is selected before the shadowbanding to maximize the dynamic range of the CCD. Exposures can vary between 0.2-5 seconds, which in combination with the 16-bit readout row capacity, results in 20+ bits combined dynamic range. The CCD is electronically shuttered, which means that the shutter is open when image rows are binned into the readout row.

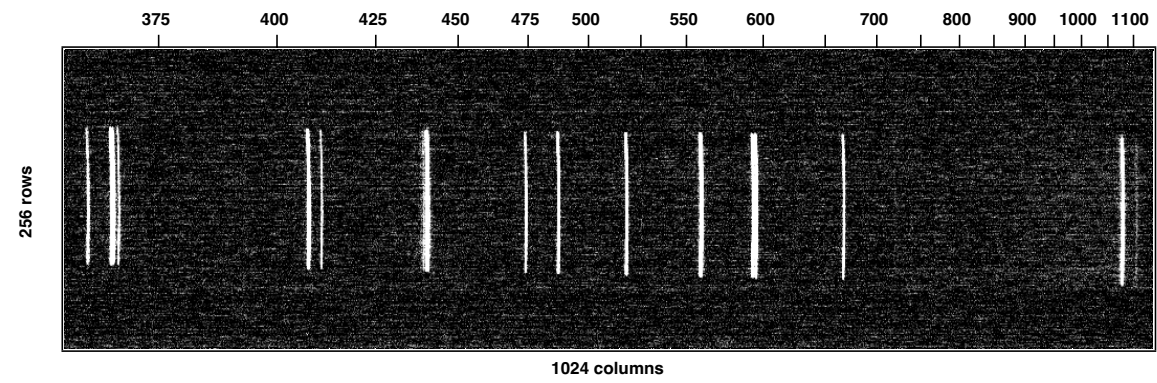

Figure 4. Mage of Hg and Cd lines recorded by the CCD 
At the end of each shadowbanding cycle the mechanical shutter is closed to acquire the dark signal at the same exposure time that was used to measure signals in four positions of the shadowband. To keep low dark counts and constant quantum efficiency, the CCD is cooled with a PID-controlled thermoelectric cooler.

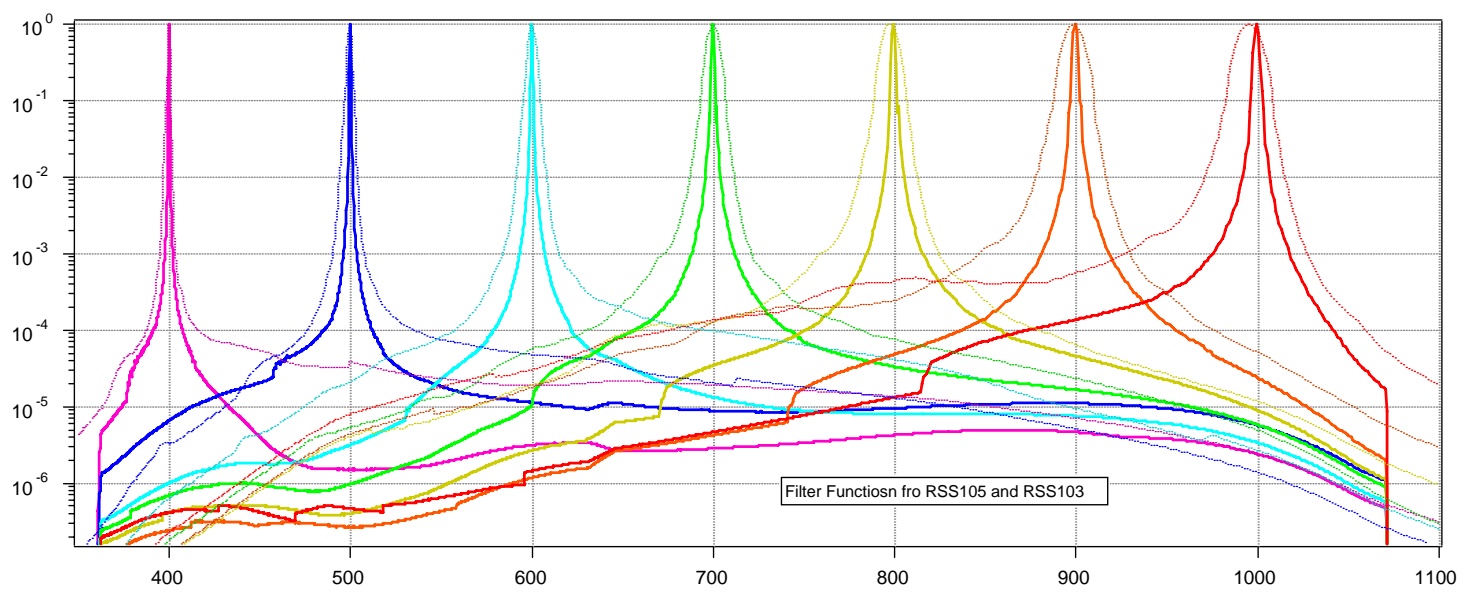

Figure 5. Filter function for RSS105 and RSS103

The optical design results in exceptionally high out-of-band rejection, which is illustrated in Figure 5, wherein filter functions that were derived from laser and spectral lamps measurements for RSS105 and the lower-resolution RSS103 are depicted.

\section{Shadowbanding method}

The diffuser is shaded at periodic intervals by a rotating shadowband. During these intervals, the total horizontal diffuse radiation is measured for each pixel simultaneously. The shadowband is moved so the diffuser is fully exposed to the sky. The total horizontal downward radiation is then measured. The difference between the total horizontal and diffuse radiation gives the downward component of the direct beam solar irradiance; from this quantity, the direct beam solar irradiance is easily calculated.

The measurements are corrected for the cosine response of the diffuser/sensor assembly as well as the "excess sky" obscured by the shadowband during the diffuse radiation measurement.

In one RSS shadowbanding cycle, five measurements (including dark signal) are performed. In Figure 6, three shadowband positions (two corrections [CorrMinus and CorrPlus] and blocked [Blocked] with respect to the diffuser) are presented. The counts of direct and diffuse horizontal irradiances are obtained with the following equations:

\section{DiffHor=[Unblocked-(CorrMinus+CorrPlus)/2+Blocked-Dark]/CosDiffCor \\ DirHor= [(CorrMinus+CorrPlus)/2-Blocked $] /$ CosDirCor}




\section{TotHor= DiffHor+ DirHor \\ DirNorm=DirHor/cos(SZA)}

Where CosDiffCor and CosDirCor are cosine corrections for diffuse and direct components, respectively. CosDiffCor is calculated for Rayleigh sky at $\mathrm{SZA}=45^{\circ}$ case.

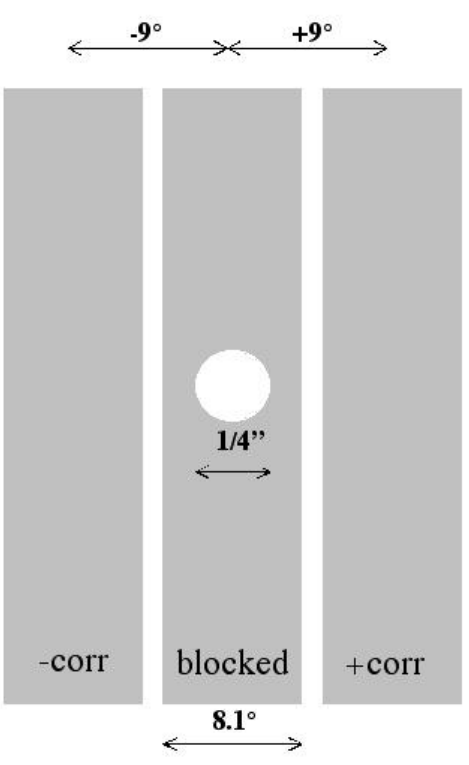

Figure 6. RSS shadowbanding geometry

The equations overestimate direct and underestimate diffuse because the correction (CorrMinus+CorrPlus)/2 does not eliminate all errors resulting from the $8.1^{\circ}$ field of view (FOV) angle. The estimates will have larger bias for aerosol size distribution $n(r)=A r^{\wedge}-k$ when $k$ is small. The estimation of these errors for geometry of the RSS has not been completed. However, a circular aperture of $8^{\circ}$ in blocked-unblocked scheme (no corrections) underestimates optical depth by $2 \%-5 \%$ for typical $\mathrm{k}=4.2-4.4$. Thus one may expect that the correction scheme used in RSS results in significantly smaller errors.

The shadowbanding geometry is well defined by the band's dimensions and its position with respect to the diffuser (see Table 3). Therefore, one can calculate RSS irradiances using any sky radiance model. This is a recommended usage of RSS data for high-quality model-measurement comparisons. 
Table 3.

\begin{tabular}{|l|c|c|c|}
\hline \multicolumn{3}{|c|}{ Shadowbanding Geometry } \\
\hline & RSS105 & RSS103 & RSS102 \\
\hline Diffuser aperture & \multicolumn{3}{|c|}{$85^{\circ}$} \\
\hline Shadowband width & \multicolumn{3}{|c|}{$3.50^{\circ}$} \\
\hline Shadowband radius & \multicolumn{3}{|c|}{ $\pm 5^{\circ}$} \\
\hline Shadowband length & \multicolumn{3}{|c|}{ yes } \\
\hline $\begin{array}{l}\text { Shadowband position at } \\
\text { corrections }\end{array}$ & Parallel with Earth axis & Parallel with Earth axis \\
\hline Shadowband axis angle & $45^{\circ}$ & \multicolumn{3}{|c|}{} \\
\hline Shadowband center on diffuser & \multicolumn{3}{|c|}{} \\
\hline
\end{tabular}

A detailed discussion of the instrument's measurement methods is found in Harrison and Michalsky (1994) and in Kiedron et al. (2002).

\section{Description of Observational Specifications}

As mentioned above, the spectral irradiances (direct, diffuse, and total) are measured at 1001 adjacent wavelengths between $360 \mathrm{~nm}$ and $1050 \mathrm{~nm}$. These measurements are made over passbands (fwhm) varying from $0.37 \mathrm{~nm}$ to $3.45 \mathrm{~nm}$ (RSS105).

\subsubsection{Specifications}

This section is not applicable to this instrument.

\subsection{Theory of Operation}

This information is currently unavailable.

\subsection{Calibration}

For calibration information, see 7.4.4 Additional Documentation

\subsubsection{Theory}

RSS105 is calibrated radiometrically with a Licor calibrator (once a month) and a Portable Calibrator (twice a month). The wavelength calibration with HgCd Oriel Calibrator was found to be unnecessary and was discontinued in March 2004. The Licor irradiance is traceable to NIST irradiance standards. Our experience indicates excellent stability and accuracy of this source (Kiedron et al. 1999). The Portable Calibrators were developed for UV spectroradiometers at ASRC. We transfer red their irradiance calibration via RSS and Licor. The current experience with them indicates excellent stability (better than $\pm 2 \%$ ) with respect to Licor in 350-1050 nm range. 
The shadowbanding method of measurement permits radiometric self-calibration of relatively stable instruments via Langley regression. For example, $\pm 5 \%$ semiannual drift of RSS102 was corrected with Vo's trends from Langley regression. Details on Langley regression and the algorithm used can be found in Harrison and Michalsky (1994).

\subsubsection{Procedures}

For further information and details, see 7.4.4 Additional Documentation

\subsubsection{History}

Because of weather conditions and other unforeseen circumstances, calibration schedule has to be flexible. At best, we expect two calibrations per month with Portable Calibrator and one calibration per month with Licor. On special occasions, we may have more than two calibrations during one day. Figure 7 depicts calibration event frequency till the end of November 2004. Since November 2005 calibration are performed once every two weeks.

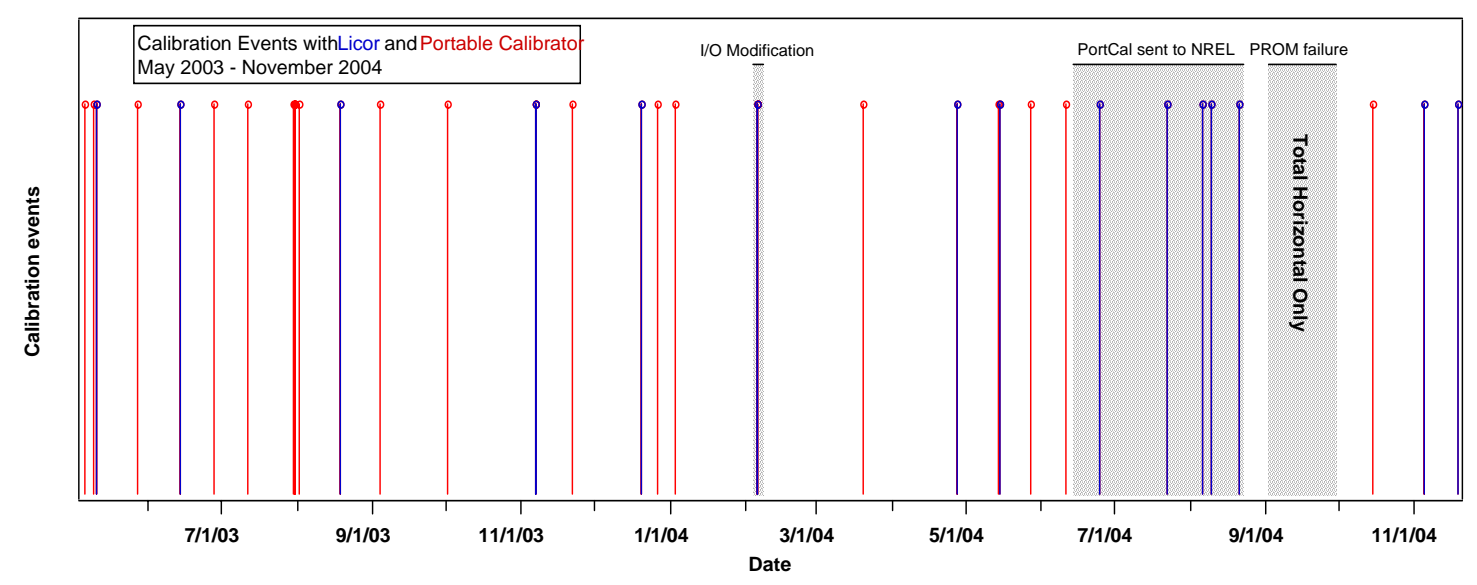

Figure 7. Calibration events till the end of November 2004

\section{See 7.4.4 Additional Documentation}

\subsection{Operation and Maintenance}

\section{Maintenance Procedures}

RSS band movement and shading when direct sun is available is checked daily. Then the diffuser is wiped with distilled water. Any malfunctions are reported to the mentor, and the mentor then initiates corrective actions (except for power recycling). 


\section{Supplemental Assessment of Instrument Calibration and Maintenance Procedures}

May 2003: RSS105 is deployed and a very rigorous calibration scheduled is instituted (calibration with Licor once a month, calibration with Portable Calibrator twice a month and spectral calibration with Oriel HgCd lamp once a month)

July 2003: Significant drift in responsivity is detected. We decide to maintain the initial calibration schedule.

February 2004: Baseline change request (BCR) 00776 (Remove the embedded Linux computer at RSS105) is implemented and the BCR is closed this month. New xtty software to acquire and parse data is launched. The change does not affect instrument basic operation; however the down time due to frequent imbedded Linux computer malfunctioning is eliminated.

March 2004: We discontinue regular wavelength calibration with HgCd Oriel calibrator. The wavelength stability of RSS105 is very good and wavelength check using Fraunhofer lines is implemented in data processing.

June 2004: Portable Calibrator is sent to Colorado and New York for UV calibrator comparison. In July and August only Licor calibrations are performed. After the Portable Calibrator's return, its fuse had to be replaced. No changes in calibrator irradiance were noticed.

September 2004: Shadowbanding does not shadow correctly. Combo board replacement cures the problem after 3 weeks of troubleshooting. Consequently, only the total horizontal spectra are available for September 2004.

September 2004: Closer analysis of calibration data shows a growth of nonlinearity in radiometric response during the first three months since deployment. The nonlinearity is characterized from data of every successful calibration event. New accounting for the nonlinearity algorithm to process data is developed. All data since the deployment are being recalculated.

April-June 2005: Shadowbanding does not shadow correctly in afternoons. Motor replacement fixes the problem. In the following periods due to incorrect shading no direct nor diffuse are reported:

All day bad shading during: $\quad$ [04/20/05, 05/03/05]

Bad shading from 1h before noon: [05/03/05, 05/26/05]

All day bad shading: [05/27/05, 05/31/05]

All day bad shading: [06/01/05, 06/03/05]

Bad shading from 1h before noon: [06/04/05, 06/16/05]

Good all day with caution: $\quad$ [06/17/05, 06/28/05]

\subsubsection{User Manual}

For installation and operating instructions, see 7.4.4 Additional Documentation

\subsubsection{Routine and Corrective Maintenance Documentation}


This section is not applicable to this instrument.

\subsubsection{Software Documentation}

All software used in RSS operation and processing is internally documented. The source files are available. All data files have ample preambles and headers.

\subsubsection{Additional Documentation}

At http://www.arm.gov/publications/tech reports/handbooks/rss/ various additional documents can be found. The list of documents is in the file AboutFilesInThisDir.doc. The documents are divided in five subdirectories: manuals/, presentations/, publications/, reports/ and stmeetings/. The following files can be found there:

\section{SUBDIRECTORY=manuals $\backslash$}

\begin{tabular}{|l|l|}
\hline \multicolumn{1}{|c|}{ FILE NAME } & \multicolumn{1}{c|}{ CONTENT } \\
\hline InstructionLicorOrielRSS.pdf & $\begin{array}{l}\text { Instructions for Using Li-Cor and Oriel Spectral } \\
\text { Calibrator with RSS }\end{array}$ \\
\hline InstructionPortCalRSS.pdf & Instructions for Using Portable Calibrator with RSS \\
\hline RSS105SignalNoise_Oct04_1pk.pdf & RSS algebra and noise \\
\hline RSSAlogithmsDiagram.pdf & Diagrams of algorithms used in RSS data processing \\
\hline Rss1024Manual.pdf & $\begin{array}{l}\text { RSS/UVRSS-1024 Rotating Shadowband Spectroradiometer } \\
\text { Installation and User Guide } \\
\text { Version 2.1 (YES, Inc.) }\end{array}$ \\
\hline UserInfo(21).pdf & $\begin{array}{l}\text { USING the RSS, low-level firmware command info UPDATED } \\
\text { 06-06-2001 By L. Harrison, ASRC, SUNY at Albany }\end{array}$ \\
\hline rss105CosCor_Aug04pk.pdf & Cosine correction in rss105 \\
\hline
\end{tabular}

\section{SUBDIRECTORY=presentations $\backslash$}

\begin{tabular}{|l|l|}
\hline \multicolumn{1}{|c|}{ FILE NAME } & \multicolumn{1}{c|}{ CONTENT } \\
\hline RSSkied_AerosolsWGBoulder2005.pdf & $\begin{array}{l}\text { P. Kiedron, “RSS: stability, calibration, Langley } \\
\text { correction, aerosols OD”, Aerosols Working Group, } \\
\text { Boulder, CO, 2005 }\end{array}$ \\
\hline RSSkied_IRF_WGAnnapolis2005.pdf & $\begin{array}{l}\text { P. Kiedron, “On RSS status”, IRF Working Group, } \\
\text { Annapolis, MD, 2005 }\end{array}$ \\
\hline RSSkied_IRF_WGSantaBarbara2004.pdf & $\begin{array}{l}\text { P. Kiedron, “Rotating Shadowband Spectroradiometer”, } \\
\text { IRF Working Group, Santa Barbara, CA, 2004 }\end{array}$ \\
\hline RSSkied_InstrMentrWGBillings2005.pdf & $\begin{array}{l}\text { P. Kiedron, “RSS Mentor Presentation”, Instrument } \\
\text { Mentor Working Group, Billings, OK, 2005 }\end{array}$ \\
\hline RSSkied_STM_IRFWGDaytonaBeach2005.pdf & $\begin{array}{l}\text { P. Kiedron, “RSS history and current status”, IRF } \\
\text { Working Group, Daytona Beach, FL, 2005 }\end{array}$ \\
\hline
\end{tabular}

\section{SUBDIRECTORY=publications $\backslash$}

\begin{tabular}{|c|c|}
\hline FILE NAME & CONTENT \\
\hline ASES2006_Gueymard.pdf & C. A. Gueymard, "PREDICTION AND VALIDATION OF \\
\hline
\end{tabular}




\begin{tabular}{|c|c|}
\hline & $\begin{array}{l}\text { CLOUDLESS SHORTWAVE IRRADIANCE FOR } \\
\text { HORIZONTAL, TILTED, OR TRACKING RECEIVERS”, Solar } \\
2006 \text { Conference, American Solar Energy Society, Denver, CO } \\
\text { (July 2006) }\end{array}$ \\
\hline ApplOpt1999_Kiedron.pdf & $\begin{array}{l}\text { Piotr W. Kiedron, Joseph J. Michalsky, Jerry L. Berndt, and Lee C. } \\
\text { Harrison, “Comparison of spectral irradiance standards used to } \\
\text { calibrate shortwave radiometers and spectroradiometers”, Appl.Opt. } \\
\text { 38, pp.2432-2439, } 1999\end{array}$ \\
\hline GRL1999_Harrison.pdf & $\begin{array}{l}\text { Lee Harrison, Mark Beauharnois, Jerry Berndt, Peter Kiedron, Joseph } \\
\text { Michalsky, Qilong Min, “The Rotating Shadowband Spectroradiometer } \\
\text { (RSS) at SGP”, J. Geophys. Res. 108: 4424, } 2003 .\end{array}$ \\
\hline GRL1999_Michalsky.pdf & $\begin{array}{l}\text { J. Michalsky, M. Beauharnois, J. Berndt, L. Harrison, P. Kiedron, and } \\
\text { Q. Min, “O2-O2 absorption band identification based on optical } \\
\text { depth spectra of the visible and near-infrared”, Geophys. Res. Lett. } \\
\text { 26, 1581-1584, } 1999\end{array}$ \\
\hline GRL1999_Min.pdf & $\begin{array}{l}\text { Qilong Min and Lee Harrison, “Joint statistics of photon path length and } \\
\text { cloud optical depth”, Geophys. Res. Lett. 26, 1425-1428, } 1999\end{array}$ \\
\hline GRL1999_Schmid.pdf & $\begin{array}{l}\text { B. Schmid, J. Michalsky, R. Halthore, M. Beauharnois, L. Harrison, J. } \\
\text { Livingston, P. Russell, B. Holben, T. Eck, A. Smirnov, “Comparison of } \\
\text { Aerosol Optical Depth from Four Solar Radiometers During the Fall } 1997 \\
\text { ARM Intensive Observation Period”, Geophys. Res. Lett. 26, 2725-2728, } \\
1999\end{array}$ \\
\hline GRL2000_Mlawer.pdf & $\begin{array}{l}\text { Mlaver, E.J., S.A. Clough, Brown, P.D., L. Harrison, J. Michalsky, P. } \\
\text { Kiedron, and T.R. Shippert, Comparison of Spectral Direct and Diffuse } \\
\text { Solar Irradiance Measurements and Calculations for Cloud-Free } \\
\text { Conditions, Geophys. Res. Lett., 27, 2653-2656, } 2000\end{array}$ \\
\hline GRL2003_Kiedron.pdf & $\begin{array}{l}\text { Kiedron, P., Berndt, J. Michalsky, J.Harrison, L., Column water vapor } \\
\text { from diffuse irradiance, Geophys. Res. Lett. Vol. 30, No. 11, 1565, } 2003\end{array}$ \\
\hline JGR2001_Kiedron.pdf & $\begin{array}{l}\text { Kiedron, P., J. Michalsky, B. Schmid, D. Slater, J. Berndt, L. Harrison, P. } \\
\text { Racette, E. Westwater and Y. Han, A Robust Retrieval of Water Vapor } \\
\text { Column in Dry Arctic Conditions Using the Rotating Shadowband } \\
\text { Spectroradiometer, , J. Geophys. Res. 106, 24,007-24,016,2001 }\end{array}$ \\
\hline JGR2001_Michalsky.pdf & $\begin{array}{l}\text { Michalsky, J.J., Q. Min, P.W. Kiedron, D.W. Slater, and J.C. Barnard, A } \\
\text { Differential Technique to Retrieve Column Water Vapor Using Sun } \\
\text { Radiometry, J. Geophys. Res., 106, D15, 17,433-17,442. } 2001\end{array}$ \\
\hline JGR2001_Min.pdf & $\begin{array}{l}\text { Qilong Min, Lee C. Harrison, Eugene E. Clothiaux, “Joint statistics of } \\
\text { photon path length and cloud optical depth: Case studies”, J. Geophys. Res, } \\
\text { 106, 7375-7385, } 2001\end{array}$ \\
\hline JGR2003_Min.pdf & $\begin{array}{l}\text { Qilong Min and Eugene E. Clothiaux, "Photon path length distributions } \\
\text { inferred from rotating shadowband spectrometer measurements at the } \\
\text { Atmospheric Radiation Measurements Program Southern Great Plains } \\
\text { site”, J. Geophys. Res, 108, NO. D15, 4465, doi:10.1029/2002JD002963, } \\
2003\end{array}$ \\
\hline JGR2005_Gianelli.pdf & S. M. Gianelli, B. E. Carlson and A. A. Lacis, "Aerosol retrievals \\
\hline
\end{tabular}




\begin{tabular}{|l|l|}
\hline & $\begin{array}{l}\text { using rotating shadowband spectroradiometer data”, J. Geophys. } \\
\text { Res, 110, D05203, doi:10.1029/2004JD005329, 2005 }\end{array}$ \\
\hline SPIE02_4815_13_kiedron.pdf & $\begin{array}{l}\text { Kiedron, P.W., L. Harrison, J.J. Michalsky, Jr., J. Schlemmer, and J.L. } \\
\text { Berndt, “Data and Signal Processing of Rotating Shadowband } \\
\text { Spectroradiometer (RSS) Data”, Proc. SPIE 4815, pp.51-57, 2002 }\end{array}$ \\
\hline
\end{tabular}

SUBDIRECTORY=reports $\backslash$

\begin{tabular}{|l|l|}
\hline \multicolumn{1}{|c|}{ FILE NAME } & \multicolumn{1}{c|}{ CONTENT } \\
\hline ETSpectraComparison_Feb1306.pdf & $\begin{array}{l}\text { P. Kiedron, “Comparison of several extraterrestrial irradiances”, } \\
\text { February 13, 2006 }\end{array}$ \\
\hline RSSDataSGPtillMay2003.pdf & Data availability from RSS102 and RSS103 prototypes \\
\hline RssPredeploy2003.pdf & $\begin{array}{l}\text { P. Kiedron, “RSS Acceptance Tests and Pre-deployment } \\
\text { Characterization”, November 17, 2003 }\end{array}$ \\
\hline RssSGP1st6months2003.pdf & $\begin{array}{l}\text { P. Kiedron, “RSS Performance Evaluation During First Six } \\
\text { Months Since Its Deployment”, November 17, 2003 }\end{array}$ \\
\hline rss\&mfrsr_Dir2DifRatio.pdf & $\begin{array}{l}\text { P. Kiedron, “Comparison of direct to diffuse ratio from RSS and } \\
\text { MFRSR”, December 13, 2005 }\end{array}$ \\
\hline
\end{tabular}

SUBDIRECTORY=stmeetings $\backslash$

\begin{tabular}{|c|c|}
\hline FILE NAME & CONTENT \\
\hline RSS_ARM2000Kiedron.pdf & $\begin{array}{l}\text { P. Kiedron, J. Berndt, J. Michalsky, Q. Min, D. Slater, "Robust retrieval of } \\
\text { water vapor at NSA using rotating shadowband spectroradiometer (RSS)", } \\
\text { ARM Science Team Meeting, } 2000 \text { (poster) }\end{array}$ \\
\hline RSS_ARM2001Harrison.pdf & $\begin{array}{l}\text { L. Harrison, J. Berndt, P. Kiedron, J. Michalsky, Q. Min, J. Schlemmer, } \\
\text { "The Solar Spectrum } 360 \text { to } 1050 \mathrm{~nm} \text { from Rotating Shadowband } \\
\text { Spectroradiometer (RSS) at the Southern Great Plains Site”, ARM Science } \\
\text { Team Meeting, } 2001 \text { (poster) }\end{array}$ \\
\hline RSS_ARM2001Kiedron1.pdf & $\begin{array}{l}\text { P. Kiedron, K. Berndt, L. Harrison, J. Michalsky, Q. Min, “Column Water } \\
\text { Vapor From Diffuse Irradiance”, ARM Science Team Meeting, } 2001 \\
\text { (poster) }\end{array}$ \\
\hline RSS_ARM2001Kiedron2.pdf & $\begin{array}{l}\text { P. Kiedron, "Spectral irradiance per interval of equal solar flux: convenient } \\
\text { spectral grid for atmospheric radiation measurement and modeling” ARM } \\
\text { Science Team Meeting, } 2001 \text { (poster) }\end{array}$ \\
\hline RSS_ARM2001Mlawer.pdf & $\begin{array}{l}\text { E. J. Mlawer, J. S. Delamere, C. J. Scott, and S. A. Clough , L. C. Harrison, } \\
\text { J. J. Michalsky, and P. W. Kiedron , H. W. Barker, T. R. Shippert, } \\
\text { "Comparison Between RSS Measurements and LBLRTM/CHARTS } \\
\text { Calculations for Clear and Cloudy Conditions”, ARM Science Team } \\
\text { Meeting 2001, (proceedings) }\end{array}$ \\
\hline RSS_ARM2003Kiedron.pdf & $\begin{array}{l}\text { P. Kiedron, J. Berndt, E. Yager, J. Schlemmer, L. Harrison, and J. } \\
\text { Michalsky, “Acceptance testing and characterization of the VIS-RSS slated } \\
\text { for permanent deployment at the SGP site”, ARM Science Team Meeting, } \\
2003 \text { (poster) }\end{array}$ \\
\hline RSS_ARM2005Kiedron.pdf & $\begin{array}{l}\text { P. Kiedron, and J. Schlemmer, "Rotating Shadowband Spectroradiometer } \\
\text { (RSS) at SGP: Performance Data Processing and Value Added Products", } \\
\text { ARM Science Team Meeting, } 2005 \text { (poster) }\end{array}$ \\
\hline RSS_ARM2006Kiedron.ppt & $\begin{array}{l}\text { Peter Kiedron, and Jim Schlemmer, "Spectrally resolved shortwave flux at } \\
\text { ARM: History and the present status of RSS", ARM Science Team }\end{array}$ \\
\hline
\end{tabular}




\subsection{Glossary}

See the ARM Glossary.

\subsection{Acronyms}

ASRC: Atmospheric Sciences Research Center

BCR: baseline change request

CCD: charge-coupled device

DQ: Data Quality

FOV: field-of-view

FWHM: Full Width at Half Maximum

MFRS: muti-filter rotating shadowband radiometer

NIST: National Institute of Standards and Technology

NSA: North Slope of Alaska

RSS: rotating shawdowband spectroradiometer

SGP: Southern Great Plains

SZA: Sun Zenith Angle

UV: ultraviolet

Also see the ARM Acronyms and Abbreviations.

\subsection{Citable References}

Gianelli, S.M., B. E. Carlson and A. A. Lacis, “Aerosol retrievals using rotating shadowband spectroradiometer data”, J. Geophys. Res, 110, D05203, doi:10.1029/2004JD005329, 2005

Harrison, L., P. Kiedron, J. Berndt, and J. Schlemmer. 2003. “Extraterrestrial Solar Spectrum 360-1050 nm from Rotating Shadowband Spectroradiometer Measurements at the Southern Great Plains (ARM) Site.” J. Geophys. Res. 108:4424.

Kiedron, P.,.J. Berndt, J. Michalsky, and L.Harrison. 2003. “Column Water Vapor from Diffuse Irradiance.” Geophys. Res. Lett. 30:1565.

Kiedron, P., and J. Michalsky. 2003. "Measurement errors in diffuse irradiance with non-Lambertian radiometers.” International J. Remote Sensing 24:237-247.

Kiedron, P.W., L. Harrison, J.J. Michalsky, Jr., J. Schlemmer, and J.L. Berndt. 2002. "Data and Signal Processing of Rotating Shadowband Spectroradiometer (RSS) Data.” Proc. SPIE 4815:58-72.

Kiedron, P., J. Michalsky, B. Schmid, D. Slater, J. Berndt, L. Harrison, P. Racette, E. Westwater, and Y. Han. 2001. "A Robust Retrieval of Water Vapor Column in Dry Arctic Conditions Using the Rotating Shadowband Spectroradiometer.” J. Geophys. Res. 106:24,007-24,016. 
Michalsky, J.J., Q. Min, P.W. Kiedron, D.W. Slater, and J.C. Barnard. 2001. "A Differential Technique to Retrieve Column Water Vapor Using Sun Radiometry.” J. Geophys. Res.106(D15):17,433-17,442.

Min, Q.L., L.C. Harrison, and E. E. Clothiaux. 2001. “Joint Statistics of Photon Pathlength and Cloud Optical Depth: Case studies.” J. Geophys. Res.106:7375-7386.

Mlawer, E.J., S.A. Clough, P.D. Brown, L. Harrison, J. Michalsky, P. Kiedron, and T.R. Shippert. 2000. "Comparison of Spectral Direct and Diffuse Solar Irradiance Measurements and Calculations for CloudFree Conditions.” Geophys. Res. Lett. 27:2653-2656.

Harrison, L., M. Beauharnois, J. Berndt, P. Kiedron, J. Michalsky, and Q. Min. 1999. "The Rotating Shadowband Spectroradiometer (RSS) at SGP.” Geophys. Res. Lett. 26:1715-1718.

Kiedron, P.W., J.J. Michalsky, J.L. Berndt, and L.C. Harrison. 1999. "Comparison of Spectral Irradiance Standards Used to Calibrate Shortwave Radiometers and Spectroradiometers.” Appl. Optics 38:2432-2439.

Michalsky, J., M. Beauharnois, J. Berndt, L. Harrison, P. Kiedron, and Q. Min. 1999. "O2-O2 Absorption Band identification Based on Optical Depth Spectra of the Visible and Near-Infrared.” Geophys. Res. Lett. 26:1581-1584.

Min, Q.L., and L. Harrison. 1999. "Joint Statistics of Photon Pathlength and Cloud Optical Depth.” Geophys. Res. Lett. 26:1425-1428.

Schmid, B., J. Michalsky, R. Halthore, M. Beauharnois, L. Harrison, J. Livingston, P. Russell, B. Holben, T. Eck, and A. Smirnov. 1999. "Comparison of Aerosol Optical Depth from Four Solar Radiometers During the Fall 1997 ARM Intensive Observation Period.” Geophys. Res. Lett. 26:2725-2728.

Harrison, L., J.Michalsky, and J. Berndt. 1994. “Automated Multifilter Rotating Shadow-Band Radiometer: An Instrument for Optical Depth and Radiation Measurements.” Appl. Optics 33:51185125.

Harrison, L., and J. Michalsky. 1994. "Objective Algorithms for the Retrieval of Optical Depths from Ground-Based Measurements.” Appl. Optics 33:5126-5132. 